\title{
Developmental Expression of Heme Oxygenase in the Rat Lung
}

\author{
PHYLLIS A. DENNERY, CHRISTEN S. LEE, BERENDERA S. FORD, YI-HAO WENG, \\ GUANG YANG, AND PAMELA A. RODGERS
}

Department of Pediatrics, Stanford University School of Medicine, Stanford, California 94305, U.S.A.

\begin{abstract}
Heme oxygenase (HO), the rate-limiting enzyme in the formation of bilirubin, is expressed in the lung and may serve as an antioxidant. This enzyme results in the formation of antioxidant bile pigments and the degradation of pro-oxidant heme. We wanted to evaluate the differences in expression of HO-1, the inducible form, and HO-2, the constitutive isoenzyme, during lung maturation and document whether lung $\mathrm{HO}$ expression was similar to that of other antioxidant enzymes. Lung total HO activity and HO-1 and HO-2 proteins as well as HO-1 and $\mathrm{HO}-2$ mRNA were evaluated in animals from $16 \mathrm{~d}$ of gestation $\left(\mathrm{e}_{16.5}\right)$ to 2 mo of age. Heme content was also evaluated because heme is the substrate of the reaction. HO-1 mRNA was maximal at $\mathrm{e}_{19.5}$ and $\mathrm{e}_{20.5}$, whereas HO-2 mRNA was not changed throughout maturation. Lung HO-1 protein was highest on the first days of life and lowest in adults, whereas HO-2 protein was maximally expressed at postnatal $\mathrm{d} 5$ and then declined to reach adult values. As to $\mathrm{HO}$ activity, there was a prenatal peak at $\mathrm{e}_{20.5}$, a
\end{abstract}

\section{ABSTRACT}

second lesser peak at $\mathrm{d} 5$, and thereafter a decline to adult values. Lung heme content was inversely correlated with $\mathrm{HO}$ activity or protein as the highest heme values were seen in adults with the lowest $\mathrm{HO}$ activity. In response to hyperoxia, HO-1 mRNA was induced only in the adult lungs. A better understanding of the maturational regulation of lung $\mathrm{HO}$ will define a role for $\mathrm{HO}$ in newborns at risk for oxygen toxicity. (Pediatr Res 53: 42-47, 2003)
HO, heme oxygenase
$\mathbf{e}_{\mathbf{n}}$, day (n) of embryonic life
VeCO, excretion of carbon monoxide
GAPD, glyceraldehyde-3-phosphate dehydrogenase
dCTP, deoxyribocytosine-triphosphate
AOE, antioxidant enzyme

\section{Abbreviations}

$\mathrm{HO}$, the rate-limiting enzyme in the degradation of heme and the formation of bilirubin, has been shown to have various roles in antioxidant defense and stress response (1). In particular, HO-1, the inducible form, is up-regulated in hyperoxia (at least in adults) (2) and in other models of oxidative stress (3-6). Neonatal animals do not up-regulate lung HO-1 mRNA in response to hyperoxia (7); however, they are able to increase lung HO-1 mRNA in other circumstances of oxidative stress (8). It is not clear whether $\mathrm{HO}$ represents a neonatal antioxidant defense, and it would be important to understand whether the expression of $\mathrm{HO}$ parallels that of other antioxidant enzymes in development.

HO-2 is the constitutive isoenzyme, which does not get up-regulated in oxidative stress. However, HO-2 has been shown to have important functions in hyperoxia, as hyperoxiaexposed HO-2 knockouts died on average $5 \mathrm{~d}$ earlier in hyper-

Received September 26, 2001; accepted June 4, 2002.

Correspondence: Phyllis A. Dennery, M.D., Department of Pediatrics, Stanford University School of Medicine, 750 Welch Road \#315, Palo Alto, CA 94304, U.S.A.; e-mail: dennery@stanford.edu

Supported by the National Institutes of Health Grant HL-52701 and HL-58752 (P.A.D.) and the Mary L. Johnson and Hess and Court Ballanger funds of Stanford University.

DOI: 10.1203/01.PDR.0000042442.08111.56 oxia than similarly exposed wild-type animals and had a 3-fold increase in serum lipid hydroperoxides indicating increased oxidative stress (9). Therefore, it is also important to evaluate the expression of HO-2 in the lung throughout gestation.

There are many examples of AOEs such as catalase, superoxide dismutase, and glutathione peroxidase, which increase in the latter third of gestation (10). It is thought that this increase represents a preparation for the relatively hyperoxic environment that the newborn will face on delivery. If $\mathrm{HO}$ serves in a similar capacity as an antioxidant, one would anticipate that its expression would be increased in the latter part of gestation in preparation for delivery. We tested this hypothesis by evaluating the level of $\mathrm{HO}$ in fetal and neonatal rats and comparing it with that of older pups and postsuckling animals. Also, the response of HO-1 to hyperoxic induction was tested in animals of various ages to see whether increased expression of HO-1 in the youngest animals would be associated with a relative resistance to hyperoxia.

\section{METHODS}

Pregnant rat dams and litters were obtained from Simonsen (Amersham Biosciences Corp., Piscataway, NJ, U.S.A.). Ani- 
mal protocols were reviewed and approved by the Animal Care Institutional Review Panel of Stanford University.

Pregnant dams were killed by $\mathrm{CO}_{2}$ narcosis. The uterus was externalized and the fetuses were extracted at $\mathrm{e}_{16.5}, \mathrm{e}_{19.5}$, and $\mathrm{e}_{20.5}$. The pups were then dissected so as to obtain the lungs. These were cleared of blood in ice-cold $1.15 \% \mathrm{KCl}$.

Pups aged 0 (day of birth), 1, 7, 14, and $21 \mathrm{~d}$ and adult male and female rats $(2 \mathrm{mo})$ were killed by $\mathrm{CO}_{2}$ narcosis, and the lungs were excised and rinsed in ice-cold $\mathrm{KCl}$ to remove any $\mathrm{Hb}$. None of the samples were visibly hemorrhagic.

\section{Hyperoxic Exposure}

In other experiments rats aged $0,1,7,14,21$, and $60 \mathrm{~d}$ were exposed to air or hyperoxia in an airtight Plexiglas cylindrical exposure chamber (Vreman Scientifics, Los Altos, CA, U.S.A.) that had a port for gas entry and access to food and water. Greater than $95 \%$ oxygen (hyperoxia) was provided with commercial cylinders (Liquid Carbonic, Chicago, IL, U.S.A.) in a flow-through system. All suckling animals were placed in the chamber along with their mother. The mothers cross-nurtured pups of the other experimental litter (i.e. air or hyperoxiaexposed) every $24 \mathrm{~h}$ to obviate the effect of hyperoxia on the dams. Food and water was available to the dams ad libitum. The pups had access to the mothers at all times except for 10-15 min daily to allow for bedding changes and chamber cleaning. Adults were similarly exposed and given free access to food and water. After $3 \mathrm{~d}$ of exposure, the animals were killed by $\mathrm{CO}_{2}$ narcosis. The lungs were excised and rinsed in cold PBS on ice to remove any blood.

\section{Assessment of HO Expression}

Tissues were analyzed for total $\mathrm{HO}$ activity by gas chromatography as previously described (11), in subdued lighting. HO activity was also estimated by measuring $\mathrm{VeCO}$ in animals before hyperoxic exposure as described (12). Values were expressed as microliters of carbon monoxide per hour per kilogram of body weight.

Polyclonal rabbit anti-rat HO-1 antibodies were raised against a $30-\mathrm{kD}$ soluble HO-1 protein expressed in Escherichia coli from rat liver cDNA (13) (gift of Angela Wilks, University of California San Francisco, CA, U.S.A.) as previously described (14). Rabbit anti-rat HO-2 antibodies were obtained from Stressgen (Vancouver, BC, Canada). Detection of HO-1 and HO-2 immunoreactive protein was performed by Western blot analysis as previously described (14). Equal loading was verified by Coomassie blue staining. Quantification was performed by densitometry (PDI, Sunnyvale, CA, U.S.A.).

Six-micrometer lung slices were incubated with a 1:25 dilution of rabbit anti-rat HO-1 overnight in a humidified chamber. After incubation, the slides were washed twice in PBS containing $0.03 \%$ saponin and $1 \%$ milk, and further incubated with a 1:50 dilution of FITC-conjugated goat antirabbit antibodies (Caltag, Burlingame, CA, U.S.A.) for $1 \mathrm{~h}$ at room temperature. Thereafter, the slides were incubated with HO-2 antibodies at a 1:25 dilution for $2 \mathrm{~h}$ at room temperature, followed by incubation in a 1:50 dilution of Texas red-labeled anti-rabbit antibodies. Lastly, some of the slides were incu- bated with a 1:25 dilution of anti-surfactant protein $\mathrm{C}$ antibodies and secondarily labeled with Cy5 anti-rabbit antibodies at a 1:100 dilution to detect type II cells. The slides were then mounted with antifade reagent in glycerol buffer (Slowfade; Molecular Probes, Eugene, OR, U.S.A.) and viewed with a Nikon fluorescence microscope (Japan) using a confocal laser scanning unit (model 2010; Molecular Dynamics, Sunnyvale, CA, U.S.A.). Excitation was set at $488 \mathrm{~nm}$ and emission at 515-545 nm for FITC. For Texas red, excitation was set at 568 $\mathrm{nm}$ and emission at $>590 \mathrm{~nm}$, and for Cy5 excitation was set at $635 \mathrm{~nm}$ and emission at $>590 \mathrm{~nm}$. Side-by-side images were processed on an SGI computer system (Molecular Dynamics). Negative controls for nonspecific binding, incubated with secondary antibody only, were processed and revealed no signal.

Lung RNA was isolated by the guanidinium thiocyanatephenol extraction method (15), quantitated spectrophotometrically at $260 \mathrm{~nm}$, and electrophoresed.

\section{Determination of HO-1 and HO-2 mRNA Levels}

Plasmid and probe preparation. The plasmid $\mathrm{pBKRHO1}$ was constructed in pBluescript II SK- using a rat HO-1 cDNA fragment prepared by reverse transcriptase-PCR as previously described (5). The housekeeping genes $\beta$-actin (American Type Culture Collection; Rockville, MD, U.S.A.) and GAPD were prepared as an EcoRI digest of the HHCPF19 plasmid. The full-length HO-2 (1269 bp) was constructed by isolation of a rat testes 972-bp HO-2 cDNA in a pRK-5 vector (gift of Solomon Snyder) with SmaI and BamHI restriction enzymes. The recovered fragment was partially digested with BamII to recover a 935-bp fragment, and a PCR-synthesized 372-bp overlapping 3 ' end fragment derived from published rat testes HO-2 sequence including the BamII site was also partially digested. The two BamII-digested fragments were blunt-end ligated The final 1269-bp product was PCR amplified. [The latter primers were constructed based on the GeneBank entry for adult rat testes HO-2 cDNA (16).] The resultant full-length cDNA was sequenced to verify that it was indeed HO-2. Labeled probes were prepared by the random primer method (17) using ${ }^{32} \mathrm{P}$-dCTP.

Northern hybridization. RNA was isolated by the guanidinium thiocyanate-phenol extraction method (15), and quantitated spectrophotometrically at $260 \mathrm{~nm}$. RNA $(20 \mu \mathrm{g})$ was electrophoresed and probed as previously described (5). For reprobing, membranes were stripped according to the manufacturer's protocol using boiling $0.5 \%$ SDS. HO- $1, \mathrm{HO}-2$, and $\beta$-actin mRNA quantification was performed by densitometry (PDI), and the ratio of HO- 1 to $\beta$-actin or GAPD was calculated. For HO-2, both bands were quantitated and the sum of both bands was used.

Membranes were probed with rat $\mathrm{HO}-1$, rat $\mathrm{HO}-2$, and the housekeeping gene GAPD (American Type Culture Collection) (14). Labeled probes were prepared by the random primer method (17) using ${ }^{32} \mathrm{P}-\mathrm{dCTP}$. Quantification of HO-1, HO-2, and GAPD mRNA was performed by densitometry (PDI), and the ratio of HO-1 to GAPD was calculated. To allow comparison between membranes, the ratio of signal to GAPD for each day was compared with the ratio for $\mathrm{d} 0$. 


\section{Determination of HO Substrate and Reaction Products}

To detect alterations in the substrate of the HO reaction, cellular heme content was determined by quantitation of the hemochrome in a reaction with pyridine in alkali. Microsomes were prepared as previously described (7) and these were washed twice with cold $0.15 \mathrm{M} \mathrm{KCl}$ to remove any $\mathrm{Hb}$, scraped and centrifuged. The samples were then resuspended in $0.9 \%$ $\mathrm{NaCl}$, mixed with a solution of $25 \%(\mathrm{v}: \mathrm{v})$ pyridine in $0.075 \mathrm{M}$ $\mathrm{NaOH}$ and scanned at absorbance 350-600 nm. The hemochromes have strong Soret bands in the range of 405-440 nm. The absorbance peak corresponding to the Soret band (414 nm) in the samples was quantitated using a published molar extinction coefficient (18). Values were expressed as $\mu \mathrm{M}$ heme/mg protein.

\section{Statistical Analysis}

For comparison among age groups, the null hypothesis that there was no difference among group means was tested by a single-factor ANOVA for multiple groups (StatView 4.02; Abacus Concepts, Inc., Berkeley, CA, U.S.A.). Statistical significance $(p<0.05)$ was determined by means of the Fisher method of multiple comparisons.

\section{RESULTS}

In all evaluations, values did not differ between male and female adults; therefore the data were analyzed as one group.

Lung HO-1 and HO-2 mRNA were evaluated throughout development and in adult animals. Lung HO-1 mRNA peaked on gestational day $\mathrm{e}_{19.5}$ to $\mathrm{e}_{20.5}$ then decreased significantly from birth onward (Fig. 1A). Two transcripts of lung HO-2 mRNA were observed. There was no change in the expression of either the 1.9- or 1.3-kb HO-2 transcript throughout gestation although the $1.3-\mathrm{kb}$ transcript was expressed at higher abundance (Fig. 1B).

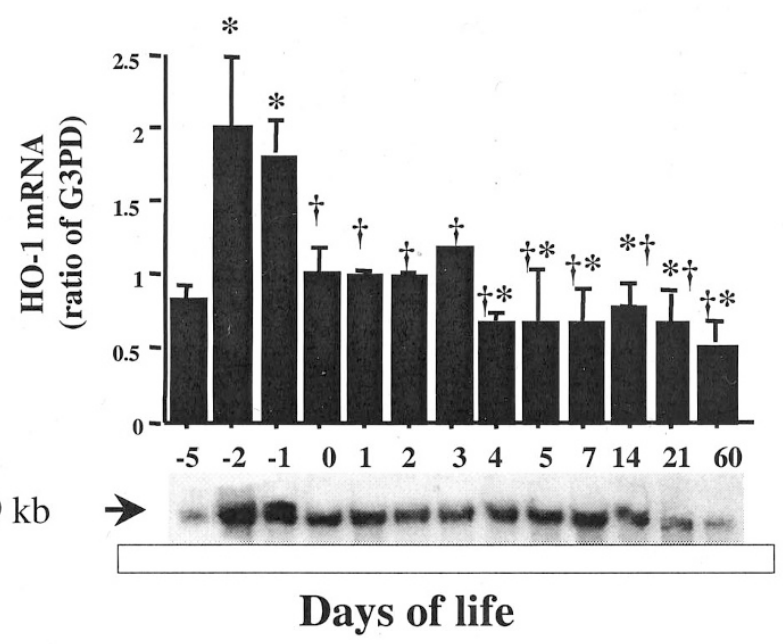

Lung HO-1 protein peaked in the first days of life then decreased until adulthood (Fig. $2 A$ ). In contrast, HO-2 protein was high prenatally, except at the end of gestation and birth $\left(\mathrm{e}_{20.5}\right.$ and 0$)$. It was again increased in the first week of life and peaked at $\mathrm{d} 5$. Thereafter, the levels of HO-2 protein decreased to adult values (Fig. $2 A$ ). The distribution of the two proteins differed in that immunoreactive HO-1 signal was initially observed in type II cells and in bronchiolar epithelium in the youngest animals and then was found predominantly in blood vessels in the adults (Fig. $2 B$ ). In contrast, HO-2 immunoreactive signal was found throughout the lung tissue (Fig. 2B).

Total lung $\mathrm{HO}$ activity was highest at day $\mathrm{e}_{20.5}$, but declined significantly at birth and in early postnatal life, then peaked to a lesser extent on d 5 and declined to adult values (Fig. 3).

Heme content was measured to evaluate whether abundance of the substrate dictated the expression of HO. Lung heme was inversely correlated to $\mathrm{HO}$ activity in that it was low prenatally and peaked on the day after birth and on $\mathrm{d} 14$, then remained relatively elevated in the adults (Fig. 4).

To determine whether the abundance of $\mathrm{HO}$ was associated with resistance to induction, animals of various age groups were exposed to hyperoxia for $3 \mathrm{~d}$. Only the adults demonstrated induction of HO-1 mRNA in response to hyperoxia (Fig. 5A). Nonetheless, d 7 animals demonstrated increased HO-1 protein (Fig. $5 B$ ) and increased $\mathrm{HO}$ activity (Fig. $5 C$ ) in hyperoxia, as did the adults. The other suckling animals (d 14 and 21) showed no increase in either lung HO-1 mRNA, protein, or activity after hyperoxia (Fig. 5).

\section{DISCUSSION}

We have demonstrated a distinct pattern of HO-1 and $\mathrm{HO}-2$ expression throughout development. As with other AOEs (10), lung $\mathrm{HO}$ activity increased before delivery, but in contrast to other AOEs, the activity was lowest in adults. There was also lack of correlation between HO-1 and HO-2 RNA, protein, and 
A

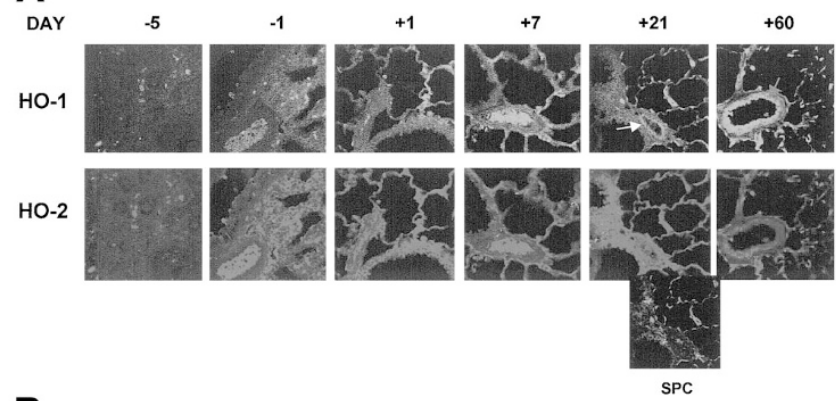

B

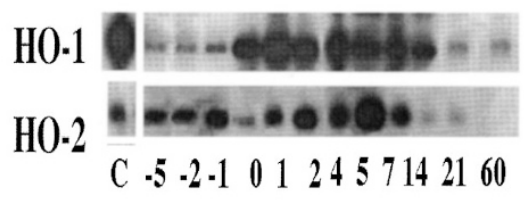

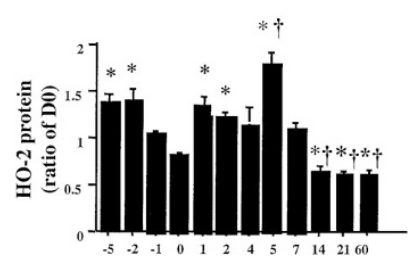

Days of life

Figure 2. A, lung immunoreactive HO protein levels in development. Top, representative of six Western blots of lung immunoreactive HO protein throughout development. ( $C$, positive control; liver from cobalt chlorideinjected rat for HO-1 and untreated testes for HO-2.) Numbers represent days of life. Negative numbers indicate number of days before birth. Bottom, lung HO protein was determined by Western blot analysis, quantitated by densitometry, and expressed as a ratio of the d 0 signal. Left, HO-1 protein; right, HO-2 protein. The numbers on the $x$ axis represent age at time of sampling. Negative numbers indicate number of days before birth. Day 0 indicates the day of birth and $\mathrm{d}-5,-2$, and -1 represent $\mathrm{e}_{16.5}, \mathrm{e}_{19.5}$, and $\mathrm{e}_{20.5}$, respectively. Values are expressed as the mean \pm SEM of six individual samples for each group. ${ }^{*} p<0.05 v s \mathrm{~d} 0 . B$, immunohistochemical detection of lung $\mathrm{HO}$ during development. Lung slices were incubated with HO-1, HO-2, and surfactant protein $\mathrm{C}$ antibodies and visualized by laser confocal microscopy. A representative example of four slides is shown. The numbers on the $x$ axis represent age at time of sampling. Negative numbers indicate number of days before birth. With maturation, HO-1 signal (top ) migrated to the endothelial cells of blood vessels (arrow), whereas HO-2 signal was ubiquitous throughout development (bottom). Type II cells are detected with Cy5-labeled anti-surfactant protein C antibodies.

activity. The lack of change in either transcript of HO-2 mRNA throughout development differs from what is observed in the liver (19) and the brain (20) and may reflect the constitutive nature of this enzyme (21) or organ-specific differences in HO-2 regulation. The lack of correlation between HO-1 mRNA and protein may be related to changes in protein or mRNA half-life (22).

Unlike the known protective AOEs, HO expression was highest in the prenatal period but showed a dramatic 50\% reduction at birth and no postnatal increase right after birth, The lack of an increase at birth does not support the hypothesis that $\mathrm{HO}$ activity affords protection against oxidative injury associated with the transition to a relatively hyperoxic postnatal environment. This has been hypothesized as the reason for

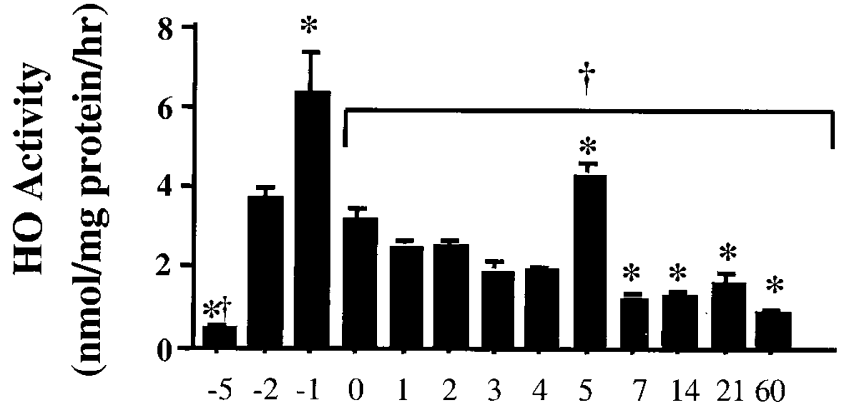

Figure 3. Lung $\mathrm{HO}$ activity in development. Total lung $\mathrm{HO}$ activity was determined by gas chromatography. The numbers on the $x$ axis represent age at time of sampling. Negative numbers indicate number of days before birth. Day 0 indicates the day of birth and $\mathrm{d}-5,-2$, and -1 represent $\mathrm{e}_{16.5}, \mathrm{e}_{19.5}$, and $\mathrm{e}_{20.5}$, respectively. Values are expressed as the mean \pm SEM of six individual samples for each group. ${ }^{*} p<0.05 v s \mathrm{~d} 0 ; \uparrow p<0.05 v s \mathrm{~d}-1$.

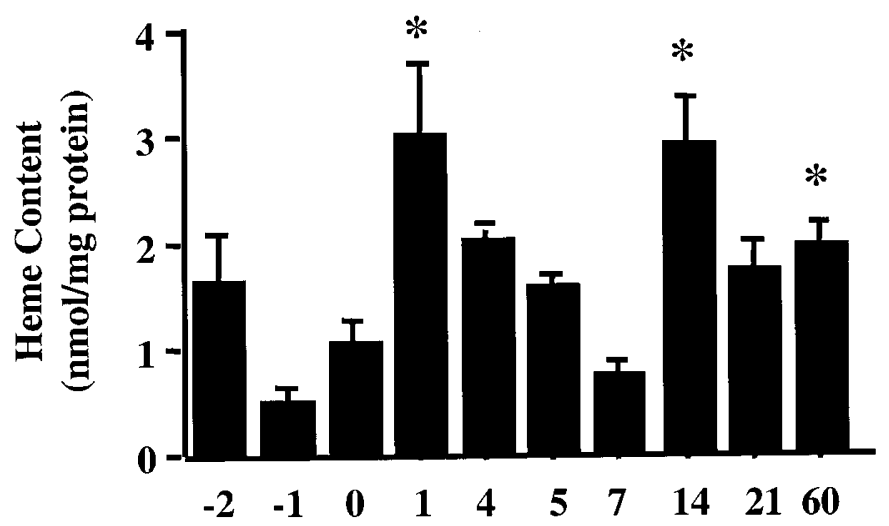

Figure 4. Microsomal lung heme development. Cellular heme was detected spectrophotometrically. The numbers on the $x$ axis represent age at time of sampling. Negative numbers indicate number of days before birth. Day 0 indicates the day of birth. Values are expressed as the mean \pm SEM of six individual samples for each group. ${ }^{*} p<0.05 v s \mathrm{~d} 0$.

the prenatal increase of other AOEs such as superoxide dismutase, glutathione peroxidase, and catalase (10). Furthermore, other lung antioxidant enzyme activity remains high in adults (10) whereas HO activity does not. The lowered lung $\mathrm{HO}$ activity in adult animals and the brisk and significant induction of lung HO-1 with hyperoxia do not appear to offer protection against hyperoxia in this model.

Unlike other AOEs, HO-1 mRNA was less readily induced in neonates exposed to hyperoxia compared with adults, and this resistance to induction persisted throughout the suckling period. This is in agreement with other models in which cells that are resistant to hyperoxia, such as $\mathrm{O}_{2} \mathrm{R} 95$ hamster fibroblast cells, also show a less ready induction of HO-1 in response to hyperoxia than do hyperoxia-susceptible parent cells (14). Some publications suggest that induction of HO-1 is not always protective against oxidative stress if this induction exceeds a certain threshold $(9,23,24)$. This suggests that beyond this threshold, no further induction is required or useful. Therefore, the neonates with already relatively high levels of HO compared with adults do not induce HO-1 further because this would be detrimental whereas adults with lower $\mathrm{HO}$ values induce HO-1 readily in hyperoxia as a protective 
A

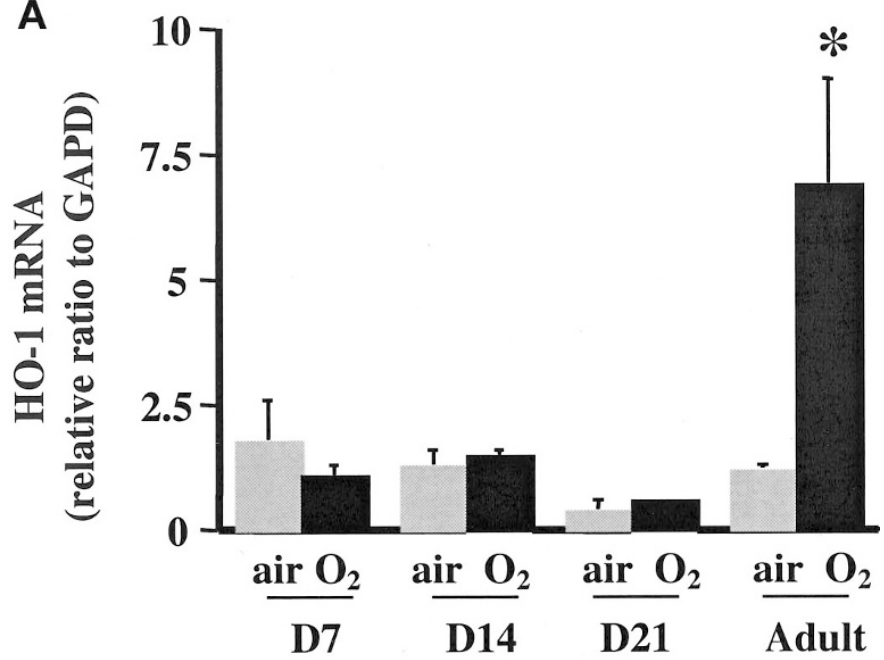

B

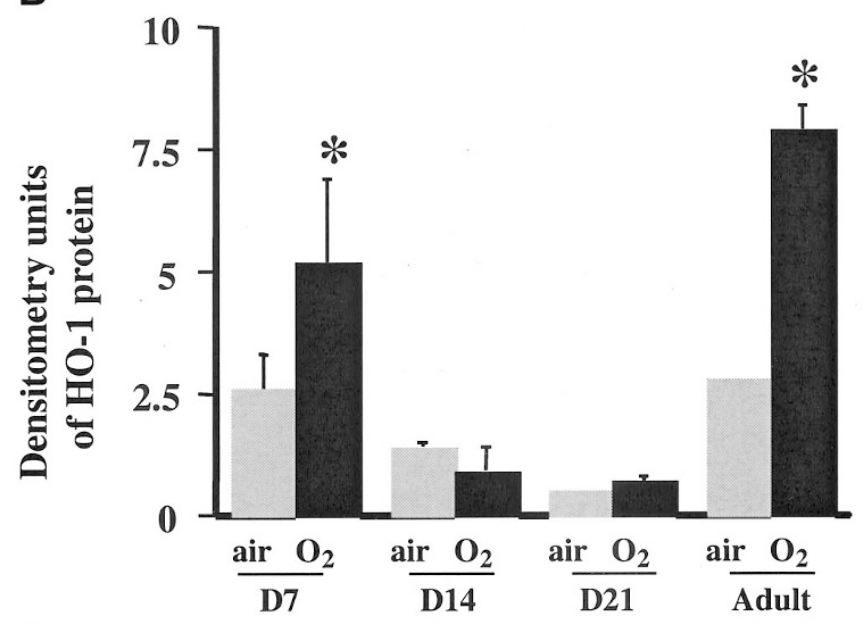

C

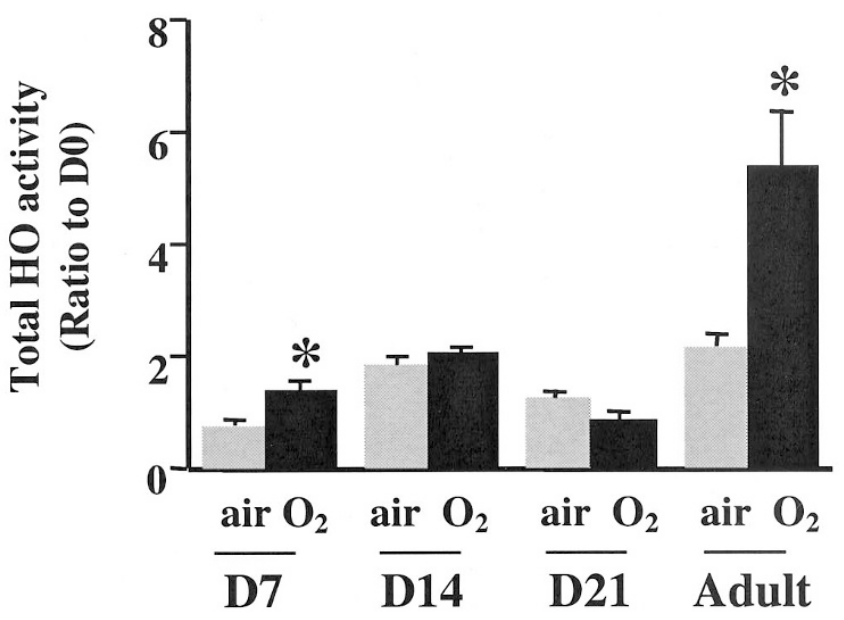

Figure 5. Effect of hyperoxia on lung HO-1 expression throughout development. Animals were exposed to hyperoxia for $72 \mathrm{~h}$ (black bars), and lung tissues were evaluated for HO-1 mRNA $(A)$, HO-1 protein $(B)$, and total HO activity $(C)$ and compared with air-exposed controls (clear bars) of similar postnatal age. The numbers on the $x$ axis represent age at the onset of hyperoxic exposure. Values represent the mean \pm SEM of five animals in each group. HO-1 mRNA is expressed as a ratio to GAPD. HO-1 protein is expressed as relative densitometry units. $\mathrm{HO}$ activity is expressed as a ratio to d 0 values to allow for comparisons. ${ }^{*} p<0.05 v s$ air. response. This hypothesis is corroborated by the data presented here; however, what regulates the inducibility during maturation is not clearly understood. We have previously reported that neonatal mice have decreased activator protein 1 binding to lung DNA in hyperoxia (25). This transcriptional factor is an important regulator of HO-1 transcription in hyperoxia (2). This lack of activator protein 1 binding in neonates may partially explain their relative resistance to $\mathrm{HO}-1$ hyperoxic induction.

Overall, the changes in $\mathrm{HO}$ mRNA, protein, and activity throughout development were not completely correlated, which suggests that there may be some posttranscriptional and posttranslational modification of HO-1 and HO-2 mRNA. This was also observed with hyperoxic exposure throughout the suckling period, as previously shown in the newly born rat pups (7). This lack of correlation between mRNA and protein has also been observed with other AOEs (26). Additionally, others have shown posttranslational activation of HO-2 in hippocampal and cortical neuronal cultures (27). Furthermore, the half-life of HO-1 mRNA and protein differ considerably, and this may help explain the discrepancy between HO-1 protein and mRNA (28). However, no one has determined whether the half-life of $\mathrm{HO}$ changes in development, and there is no clear understanding of posttranslational control of HO-1 or $\mathrm{HO}-2$ protein.

Because heme is the substrate of the HO reaction, it could be that the lung $\mathrm{HO}$ activity depends on the availability of the substrate. It has been well documented that heme can mediate induction of HO-1 $(22,29)$. This did not appear to be the case in this study because lung heme levels were relatively low in the newly born animals compared with adults, yet they had the highest level of $\mathrm{HO}$ activity. However, the fact that heme levels were negatively correlated to the $\mathrm{HO}$ activity may simply indicate increased heme utilization when $\mathrm{HO}$ activity is highest. What regulates the increased $\mathrm{HO}$ activity in the newborn compared with adults is not yet clear. This remains to be determined.

\section{CONCLUSIONS}

In summary, overall lung $\mathrm{HO}$ expression was highest prenatally and lowest in adulthood. This was also associated with the relative resistance to further hyperoxic induction of HO-1 in the neonatal animals. We speculate that the expression of $\mathrm{HO}$ is tightly regulated in the lung to maintain the optimal level that provides protection against oxidative stress.

Acknowledgments. We thank Arthur Tatarov for his expert technical assistance and Lisa Raskin for preparing the slides for immunohistochemistry.

\section{REFERENCES}

1. Applegate LA, Luscher P, Tyrrell RM 1991 Induction of heme oxygenase: a general response to oxidant stress in cultured mammalian cells. Cancer Res 51:974-978

2. Lee PJ, Alam J, Sylvester SL, Inamdar N, Otterbein L, Choi AM 1996 Regulation of heme oxygenase-1 expression in vivo and in vitro in hyperoxic lung injury. Am J Respir Cell Mol Biol 14:556-568

3. Keyse SM, Applegate LA, Tromvoukis Y, Tyrrell RM 1990 Oxidant stress leads to transcriptional activation of the human heme oxygenase gene in cultured skin fibroblasts. Mol Cell Biol 10:4967-4969 
4. Aizawa T, Ishizaka N, Taguchi J, Nagai R, Mori I, Tang SS, Ingelfinger JR, Ohno M 2000 Heme oxygenase- 1 is upregulated in the kidney of angiotensin II-induced hypertensive rats: possible role in renoprotection. Hypertension 35:800-806

5. Anning PB, Chen Y, Lamb NJ, Mumby S, Quinlan GJ, Evans TW, Gutteridge JM 1999 Iron overload upregulates haem oxygenase 1 in the lung more rapidly than in other tissues. FEBS Lett 447:111-114

6. Beschorner R, Adjodah D, Schwab JM, Mittelbronn M, Pedal I, Mattern R, Schluesener HJ, Meyermann R 2000 Long-term expression of heme oxygenase(HO-1, HSP-32) following focal cerebral infarctions and traumatic brain injury in humans. Acta Neuropathol (Berl) 100:377-384

7. Dennery PA, Rodgers PA, Lum MA, Jennings BC, Shokoohi V 1996 Hyperoxic regulation of lung heme oxygenase in neonatal rats. Pediatr Res 40:815-821

8. Tom DJ, Rodgers PA, Shokoohi V, Stevenson DK, Dennery PA 1996 Hepatic heme oxygenase is inducible in neonatal rats during the early postnatal period. Pediatr Res 40:288-293

9. Dennery PA, Yang G, Tatarov A, Lee CS, Shegog ML, Spitz DR, Poss KD 1998 Lung oxidative injury in the absence of heme oxygenase- 2 in mice. J Clin Invest 101:1001-101

10. Frank L, Sosenko IR 1987 Prenatal development of lung antioxidant enzymes in four species. J Pediatr 110:106-110

11. Vreman HJ, Stevenson DK 1988 Heme oxygenase activity as measured by carbon monoxide production. Anal Biochem 168:31-38

12. Vreman HJ, Rodgers PA, Gale R, Stevenson DK 1989 Carbon monoxide excretion a an index of bilirubin production in rhesus monkeys. J Med Primatol 18:449-460

13. Wilks A, Ortiz de Montellano PR 1993 Rat liver heme oxygenase: high leve expression of a truncated soluble form and nature of the meso-hydroxylating species. J Biol Chem 268:22357-22362

14. Dennery PA, Wong HE, Sridhar KJ, Rodgers PA, Sim JE, Spitz DR 1996 Differences in basal and hyperoxia-associated $\mathrm{HO}$ expression in oxidant-resistant hamster fibroblasts. Am J Physiol 271:L672-L679

15. Chomczynski P, Sacchi N 1987 Single-step method of RNA isolation by acid guanidinium thiocyanate-phenol-chloroform extraction. Anal Biochem 162:156-159

16. Rotenberg MO, Maines MD 1991 Characterization of a cDNA-encoding rabbit brain heme oxygenase- 2 and identification of a conserved domain among mammalian heme oxygenase isozymes: possible heme-binding site? Arch Biochem Biophys 290:336-344
17. Feinberg AP, Vogelstein B 1983 A technique for radiolabeling DNA restriction endonuclease fragments to high specific activity. Anal Biochem 132:6-13

18. Fuhrop JH, Smith KM 1975 Hemes determination as pyridine hemochromes. In: Smith KM (ed) Porphyrins and Metalloporphyrins. Elsevier Scientific, New York, pp 804-807

19. Sun Y, Maines MD 1990 Heme oxygenase-2 mRNA: developmental expression in the rat liver and response to cobalt chloride. Arch Biochem Biophys 282:340-345

20. Sun Y, Rotenberg MO, Maines MD 1990 Developmental expression of heme oxygenase isozymes in rat brain: two HO-2 mRNAs are detected. J Biol Chem 265:8212-8217

21. McCoubrey Jr WK, Maines MD 1994 The structure, organization and differential expression of the gene encoding rat heme oxygenase-2. Gene 139:155-161

22. Srivastava KK, Cable EE, Donohue SE, Bonkovsky HL 1993 Molecular basis for heme-dependent induction of heme oxygenase in primary cultures of chick embryo hepatocytes: demonstration of acquired refractoriness to heme. Eur J Biochem 213:909-917

23. Suttner DM, Sridhar KJ, Lee CS, Tamura T, Hansen TN, Dennery PA 1999 Protective effects of transient HO-1 overexpression on susceptibility to oxygen toxicity in lung cells. Am J Physiol 276:L463-L470

24. Dwyer BE, Lu SY, Laitinen JT, Nishimura RN 1998 Protective properties of tin- and manganese-centered porphyrins against hydrogen peroxide-mediated injury in rat astroglial cells. J Neurochem 71:2497-2504

25. Yang G, Madan A, Dennery PA 2000 Maturational differences in hyperoxic AP-1 activation in rat lung. Am J Physiol Lung Cell Mol Physiol 278:L393-L398

26. Clerch LB, Massaro D 1992 Rat lung antioxidant enzymes: differences in perinatal gene expression and regulation. Am J Physiol 263:L466-L470

27. Dore S, Takahashi M, Ferris CD, Zakhary R, Hester LD, Guastella D, Snyder SH 1999 Bilirubin, formed by activation of heme oxygenase-2, protects neurons against oxidative stress injury. Proc Natl Acad Sci USA 96:2445-2450

28. Lutton JD, da Silva JL, Moqattash S, Brown AC, Levere RD, Abraham NG 1992 Differential induction of heme oxygenase in the hepatocarcinoma cell line (Hep3B) by environmental agents. J Cell Biochem 49:259-265

29. Balla J, Nath KA, Balla G, Juckett MB, Jacob HS, Vercellotti GM 1995 Endothelial cell heme oxygenase and ferritin induction in rat lung by hemoglobin in vivo. Am J Physiol 268:L321-L327 